\title{
Corneal epitheliopathy under diagnosed: toxic, nutritional diabetic epitheliopathy
}

\section{Epiteliopatías corneales subdiagnosticadas: epiteliopatías tóxica, nutricional y diabética}

\author{
Arturo Ramírez-Miranda* and Ricardo Blas-Medina
}

Department of Cornea and Refractive Surgery, Institute of Ophthalmology «Fundación Conde de Valenciana» IAP, Mexico City, Mexico

\begin{abstract}
There are many causes of corneal epitheliopathies, however, the rare causes are underdiagnosed due to the little knowledge that exists about them. Among these the most frequent is undoubtedly the toxic epitheliopathy, due to the misuse or treatment of some topical medication, exerting its toxic effects directly to cause a superficial punctate keratopathy, or indirectly causing inflammation and interfering with the migration of the epithelial limbal cells. There is a wide range of agents that can cause toxic epitheliopathy, the most known benzalkonium chloride (BAK), highly toxic to the corneal epithelium, strongly associated with toxic epitheliopathy, allergic conjunctivitis and blepharitis. There have been described toxic epithelopathies secondary to chemotherapy specifically with monoclonal antibodies that inhibit the epidermal growth factor receptor (EGFR). The epitheliopathy secondary to vitamin A deficiency is a very important clinical aspect in this pathology, causing an instability of the precorneal tear layer causing a punctate epitheliopathy, which can progress to epithelial defects, stromal edema and keratinization. Diabetes mellitus can lead to several ocular complications, among which is the diabetic epitheliopathy that includes superficial punctate keratopathy and persistent epithelial defects, having an important clinical impact due to the symptoms produced from foreign body sensation to visual impairment. It is important to know this entities for its proper diagnosis and treatment. Search intentionally in ophthalmological practice in cases of persistent epitheliopathies or treatment resistant.
\end{abstract}

Key words: Corneal Epithelium. Benzalkonium Compounds. Allergic Conjunctivitis. Blepharitis. Inflammation. Diabetes Mellitus.

\section{Resumen}

Existen muchas causas de epiteliopatías corneales; sin embargo, las causas poco frecuentes son infradiagnosticadas debido al poco conocimiento que existe acerca de ellas. Dentro de éstas la más frecuente es, sin duda, la epiteliopatía tóxica, debida al mal uso o sobretratamiento de alguna medicación tópica. Ejerce sus efectos tóxicos directamente ocasionando una queratopatía punteada superficial o indirectamente provocando inflamación e interfiriendo en la migración de células basales epiteliales del limbo. Existe un amplio rango de agentes que pueden provocar epiteliopatía tóxica, el más conocido de los cuales es el cloruro de benzalconio (BAK), altamente tóxico en el epitelio corneal y fuertemente asociado con epiteliopatía tóxica, conjuntivitis alérgica y blefaritis. En la literatura se han reportado epiteliopatías tóxicas secundarias a quimioterapias específicamente con anticuerpos monoclonales que inhiben el receptor del factor de crecimiento epidérmico (EGFR). En cuanto a las causas nutricionales, la epiteliopatía secundaria a deficiencia de vitamina $A$ es un aspecto clínico muy

Correspondence:

*Arturo Ramírez-Miranda

Chimalpopoca, 14

Date of reception: 04-10-2017

Date of acceptance: 20-02-2018

DOI: 10.24875/RMOE.M18000024
Available online: 16-07-2018 Rev Mex Oftalmol (Eng). 2018;92(4):145-151 www.rmo.com.mx license (http://creativecommons.org/licenses/by-nc-nd/4.0/). 
importante en esta enfermedad, que ocasiona una inestabilidad de la capa lagrimal precorneal provocando una epiteliopatía punteada, que puede progresar a defectos epiteliales, edema estromal y queratinización. La diabetes mellitus (DM) puede llevar a varias complicaciones oculares, entre las cuales se encuentra la epiteliopatía diabética que comprende la queratopatía punteada superficial y defectos epiteliales persistentes, con un impacto clínico importante debido a los síntomas que produce, desde sensación de cuerpo extraño hasta baja visual. Es importante conocer este tipo de enfermedades para su adecuado diagnóstico y tratamiento. Deben buscarse intencionadamente en la práctica oftalmológica en los casos de epiteliopatías persistentes o refractarias al tratamiento convencional.

Palabras clave: Epitelio corneal. Compuestos de benzalconio. Conjuntivitis alérgica. Blefaritis. Inflamación. Diabetes mellitus.

\section{Introduction}

Corneal epitheliopathy has a diverse range of causes and clinical presentations that generate a challenge in the ophthalmological practice. Uncommon causes are under-diagnosed due to little awareness. Therefore, it is very important to recognize and diagnose them in a timely manner for an effective treatment.

\section{Toxic epitheliopathy}

Topical medication is a very specific treatment in ophthalmological clinical practice. Ophthalmic drops have several factors that can affect the ocular surface. Because the volume of a drop is too high for the conjunctival sac, the components of the tear, including electrolytes, proteins and mucin, are removed from the tear film. These drops can also alter the $\mathrm{pH}$ and osmotic pressure. In addition, it is known that they inhibit the proliferation, regeneration and renewal of the corneal epithelium 1 .

Self-medication is a common practice in Mexico, especially in people of low socioeconomic status who rarely seek a specialist for proper management of their medical problems. In addition to this, some patients borrow topical medications from relatives or friends. When they apply them and obtain unfavorable results, patients seek professional help.

It has been shown that the risk of having adverse drug reactions is related to the number of prescribed medications ${ }^{2}$. Consequently, the use of multiple medications increases the probability of drug interactions, toxicity, and combinations that may be synergistic. However, the ophthalmologists may be the culprits of the overtreatment of patients, with certain topical medications that can have deleterious effects on ocular tissues.

\section{Pathophysiology}

A toxic substance can be defined as any substance that due to its chemical reaction causes structural damage or alteration in the function, above any therapeutic effect ${ }^{3}$. Drugs can be directly toxic to the corneal epithelium, damaging its structure and altering its function, accompanied or not by an inflammatory response ${ }^{4}$. Most of these drugs exert their toxic effects through multiple proposed mechanisms: directly by causing superficial punctate keratopathy or indirectly causing inflammation as ring-like stromal infiltrates in cases of overuse of anesthetics or anti-inflammatories ${ }^{5}$. Some topical medications may interfere with the migration of limbal basal epithelial cells, especially if epithelial defects exist, causing a delay in epithelialization and promoting stromal infiltrates.

Ophthalmic drops are composed of the active drug, as well as preservatives and buffer solutions. BAK has been used as a conservative for many years ${ }^{6}$. It is very soluble in water and easy to handle. Because BAK has a strong antibacterial activity, these drops can be safe for very long periods. However, BAK is highly toxic to the corneal epithelium and is strongly associated with toxic epitheliopathy and allergic conjunctivitis or blepharitis?.

\section{Toxicity induced by ophthalmic drugs}

Toxicity to the corneal epithelium secondary to topical medications commonly occurs after the use of antiglaucoma drugs, anesthetics and, to a lesser extent, topical antibiotics ${ }^{5,8}$ (Fig. 1).

Non-steroidal anti-inflammatory drugs (NSAIDs) can also cause severe ocular surface complications ${ }^{9}$. There is a wide range of agents that can cause toxic epitheliopathy; however, there are some known specifically for this characteristic, including antibiotics such as aminoglycosides (neomycin and gentamicin), fluoroquinoIones (especially ciprofloxacin), ocular hypotensives (especially timolol and dorzolamide), NSAIDs (particularly diclofenac) and topical anesthetics. Ophthalmic preservatives such as thimerosal and BAK have been extensively associated with toxic epitheliopathy. While thimerosal is no longer contained in most ophthalmic 


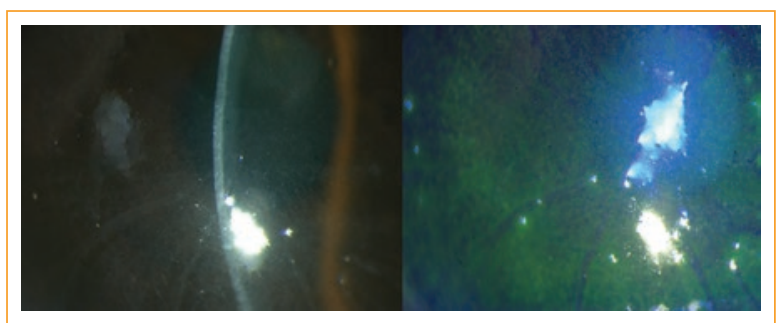

Figure 1. Slit lamp photograph of the corneal surface (A) and with fluorescein staining (B) of a patient with toxic epitheliopathy secondary to topical drops of $0.3 \%$ ciprofloxacin (image taken from the photographic archive of the Cornea and Refractive Surgery Department of the Institute of Ophthalmology "Fundación Conde de Valenciana").

drugs and contact lens solutions in the US, BAK is the most commonly used conservative in ophthalmic drugs, despite its recognized hypersensitivity potential ${ }^{4}$.

\section{Toxicity secondary to other causes}

There may be a toxic epitheliopathy because of accidental or unwanted contact of caustic substances with the ocular surface. This variety ranges from substances that can be found at home (chlorine, ammonium, alcohol and kerosene) to chemical weapons (pepper spray [Oleoresin capsicum] or tear gas [ortho chlorobenzylidene malononitrile]) and toxic substances produced by animals or plants (poison, plant and animal toxins) $)^{2,10}$. These agents are less likely to cause a simple type I hypersensitivity reaction and more commonly cause damage to the epithelial cells due to direct toxicity, followed by secondary inflammatory effects ${ }^{11}$.

In the literature, epitheliopathies and corneal perforations secondary to chemotherapy have been reported, specifically with monoclonal antibodies that inhibit EGFR, a transmembrane protein with a domain for the binding of the extracellular ligand associated to an intracellular protein tyrosine kinase, which regulates proliferation, differentiation, migration and cellular apoptosis This treatment is used in carcinomas refractory to treatment or in patients intolerant to chemotherapy. Due to the increased interest in new chemotherapies, it is important that ophthalmologists recognize and manage the potential side effects of these treatments ${ }^{12}$.

\section{Clinical features}

There is a wide variety of corneal manifestations associated with toxic keratitis, ranging from minimal punctate epitheliopathy to corneal ulceration and necrosis. ${ }^{13}$ Patients often recognize a causal agent, and report a history of inadvertent (cleaning chemicals) or intentional (instillation of a topical medication) eye contact.

Toxic epitheliopathy can be uni- or bilateral and affect any individual, regardless of age, race or gender. Patients may commonly present some degree of ocular discomfort, which may manifest as itching, burning, photophobia, foreign body sensation or pain. Blurred vision and tearing are also often associated with this entity ${ }^{14}$.

The classic clinical finding is punctate epitheliopathy, which may or may not be confluent and show a specific pattern by fluorescein staining, predominantly in the inferonasal quadrant, where the maximum contact time between the drug and the ocular surface occurs ${ }^{13}$ (Fig. 2). Filamentous keratopathy or pseudo dendrites are also observed in some cases ${ }^{15}$.

The corneal epithelium can be opaque and edematous, and sometimes a hurricane keratopathy may be observed $^{16}$. In more advanced cases, occasionally a spiral pattern is observed (vortex keratopathy) (Fig. 3). Severe or prolonged exposure can lead to persistent epithelial defects, ulcerative keratitis (Fig. 4), corneal thinning and perforation ${ }^{13,17}$.

\section{Diagnosis}

There are several tests designed to evaluate the toxic effects of ophthalmic preparations on the ocular surface, but most of them are not practical, not available or difficult to perform in the clinical context ${ }^{18}$.

\section{Impression cytology}

Impression cytology with topical anesthesia provides a homogenous cell layer for histological studies with an almost intact architecture and preserved cell junctions. Immunostaining protocols are able to differentiate epithelial, goblet and inflammatory cells. In addition, they can be used for cytometry analysis. Some studies have shown that the HLA-DR (human leukocyte antigens) class II antigens and IL-(interleukin) 6, 8 and 10 are highly expressed in the conjunctival epithelium of patients with history of prolonged antiglaucoma treatment ${ }^{19}$.

The diagnosis of toxic epitheliopathy is commonly based on the clinical history and evolution of the disease, as well as on current clinical manifestations. It should be taken into consideration as a differential 


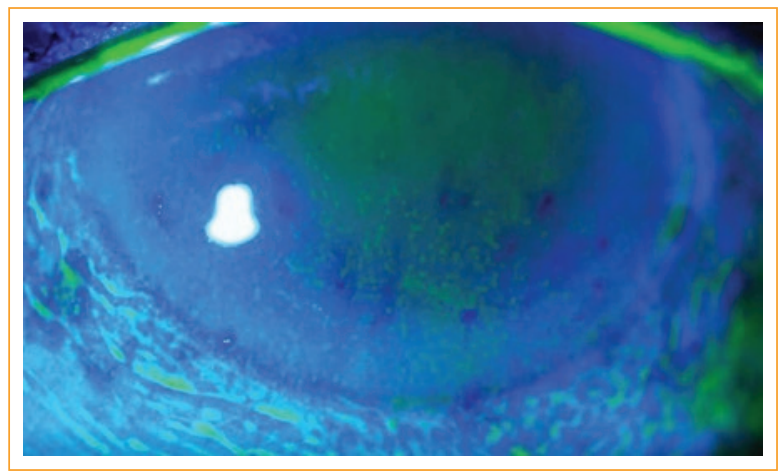

Figure 2. Fluorescein corneal staining with cobalt blue filter of a patient with toxic epitheliopathy secondary to difluprednate, showing inferonasal location (image taken from the photographic archive of the Cornea and Refractive Surgery Department of the Institute of Ophthalmology "Fundación Conde de Valenciana").

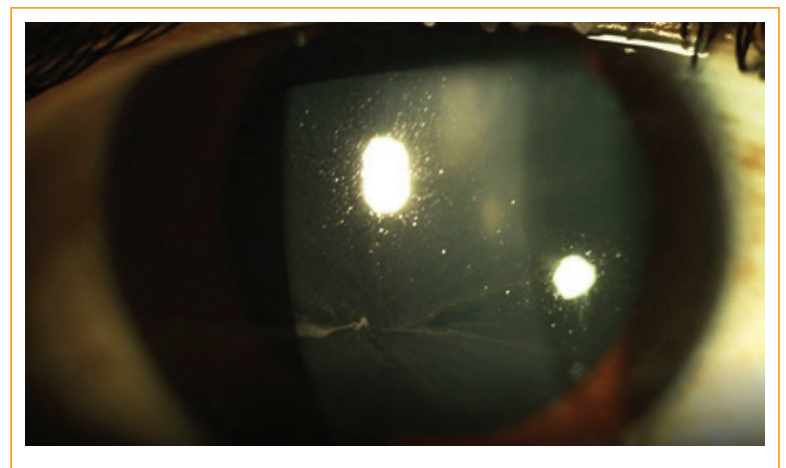

Figure 3. Slit lamp photograph with diffuse illumination of the corneal surface of a patient with vortex keratopathy associated to systemic amiodarone (image taken from the photographic archive of the Cornea and Refractive Surgery Department of the Institute of Ophthalmology "Fundación Conde de Valenciana").

diagnosis when patients report initiating a new ophthalmic treatment, cosmetic agent or contact lens product in the previous weeks ${ }^{20}$.

\section{Treatment}

When establishing a toxic agent, the most important consideration for treatment is to discontinue the substance or causal drug. Treatment will depend on the time of exposure, as well as the severity of the ocular surface disease. The drug must be discontinued, if possible, or replace it with preservative-free formulations. Contact lenses should be used with caution, as they

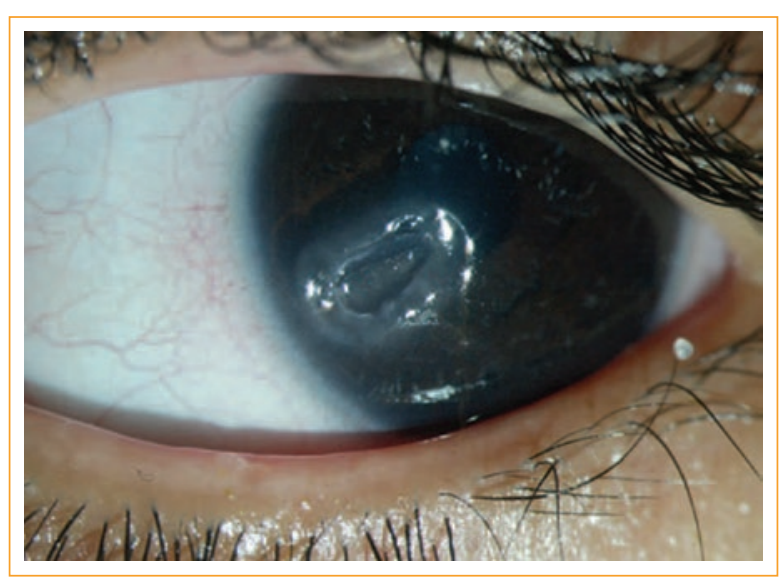

Figure 4. Slit lamp photograph of an ulcer secondary to prolonged use of topical tetracaine hydrochloride (image taken from the photographic archive of the Cornea and Refractive Surgery Department of the Institute of Ophthalmology "Fundación Conde de Valenciana").

can act as a toxic reservoir. In case of moderate illness, preservative-free lubricants can be used to alleviate symptoms. A topical steroid can be used in most symptomatic patients ${ }^{13}$. A more advanced disease such as a persistent epithelial defect may require other types of procedures such as tarsorraphy, amniotic membrane graft or conjunctival flaps. Keratoplasty may be an option for corneal ulcerations with impending risk of perforation or necrosis ${ }^{21}$.

\section{Nutritional epitheliopathies}

\section{Introduction}

Nutrition-related corneal diseases have been recognized for a long time and are a very common cause of new cases of blindness every year.

Manifestations of vitamin A deficiency remain the leading cause of childhood blindness in developing countries $^{22}$. The deficiency of this fat-soluble vitamin or its metabolites manifests in two ways: nictalopia and a spectrum of ocular disorder known as xerophthalmia, including epidermal keratinization and squamous metaplasia of the cornea and conjunctiva ${ }^{23}$. Epitheliopathy secondary to vitamin A deficiency is a very important clinical aspect in this disease.

For a long time vitamin $A$ has been recognized for improving skin healing. Numerous studies have shown that it accelerates epithelial migration and the formation of granulation tissue, and reverses the delay in healing induced by corticosteroids ${ }^{24,25}$. 


\section{Clinical features}

Vitamin A deficiency promotes instability of the precorneal tear film that causes punctate epitheliopathy, which can progress to epithelial defects, keratinization and stromal edema ${ }^{23}$. Without treatment, epithelial defects progress to partial or full-thickness ulcerations and may predispose to bacterial infections. Keratomalacia is a full-thickness liquefactive necrosis of the cornea that, together with vitamin A deficiency, is frequently associated with a preceding systemic factor such as measles or severe protein malnutrition. ${ }^{26}$

When the disease is active, the cornea may have a ground-glass appearance on retro illumination (Fig. 5). This is more prominent in areas of dense punctate keratopathy, the same sites where the tear film break-up time is shorter. Dense, irregular patches suggesting an agglomeration of bacteria or fragmented keratin can be observed, as in Bitot's spots. Plaques, xerosis, and corneal opacity usually occur in both eyes (Fig. 6).

\section{Treatment}

Recommended treatments include $0.01-0.1 \%$ trans retinoic acid ${ }^{27,28}$. Effectiveness does not increase with higher doses $(0.25 \%)^{29}$. By increasing the dose and frequency of application, the likelihood of developing Meibomian gland dysfunction and blepharoconjunctivitis also increases, although this is reversible after discontinuing retinoic acid. Studies have shown that treatment must start with three or four applications per day, decreasing up to once a day or every two days as symptoms improve (usually in 2-3 weeks) ${ }^{30}$.

\section{Diabetic epitheliopathy}

\section{Introduction}

DM can lead to several ocular complications, among which diabetic epitheliopathy encompasses superficial punctate keratopathy, recurrent corneal erosions and persistent epithelial defects ${ }^{31}$ (Fig. 7). In addition to this, most diabetic patients suffer from dry eye syndrome.

In some cases, diabetic epitheliopathy is difficult to treat and can induce abnormalities in the quantity and quality of tear secretion, a decrease in corneal sensitivity and poor adhesion of regenerated epithelial cells ${ }^{32}$.

\section{Clinical features}

Corneal diseases are a common condition that include several alterations, especially epithelial and

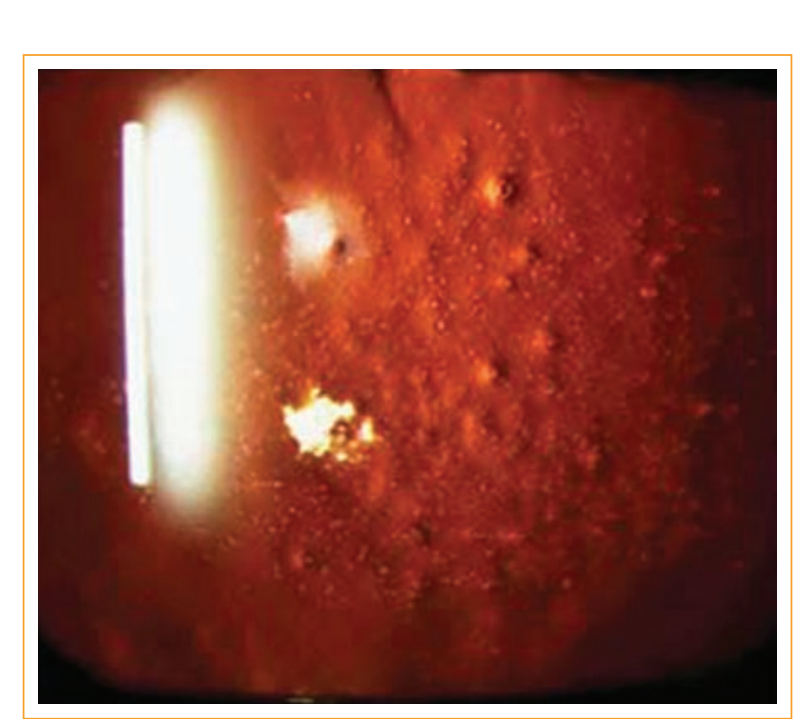

Figure 5. Corneal surface photograph showing a groundglass appearance on retro illumination in a patient with an epitheliopathy secondary to vitamin A deficiency (image taken from the photographic archive of the Cornea and Refractive Surgery Department of the Institute of Ophthalmology “Fundación Conde de Valenciana").

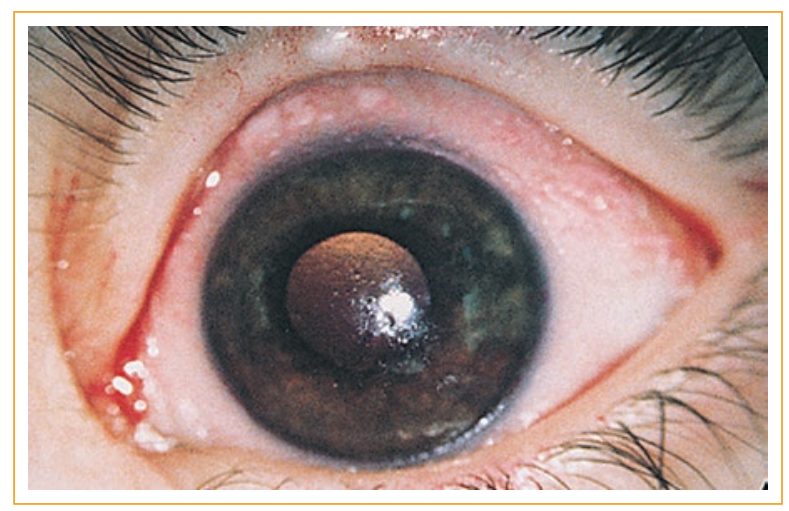

Figure 6. Ocular surface photograph of a patient with vitamin $A$ deficiency and a diagnosis of xerophthalmia (image taken from the photographic archive of the Cornea and Refractive Surgery Department of the Institute of Ophthalmology "Fundación Conde de Valenciana").

endothelial. Corneal epitheliopathy manifests as punctate keratitis, decreased adherence to the basement membrane and corneal hypoesthesia. It is of clinical interest due to the symptoms it produces: foreign body sensation, red eye, pain and visual fluctuations s. $^{33}$.

The most important damage to the cornea occurs in the cells of the epithelial basement membrane (with regenerative abilities). The diabetic cornea also suffers 


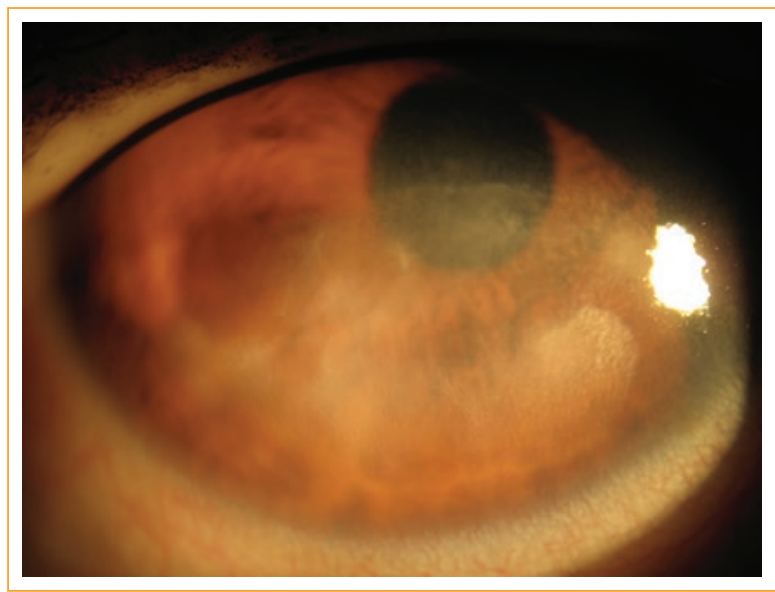

Figure 7. Slit lamp photograph with diffuse illumination of the corneal surface showing a persistent epithelial defect of a patient with uncontrolled type 2 DM (image taken from the photographic archive of the Cornea and Refractive Surgery Department of the Institute of Ophthalmology "Fundación Conde de Valenciana").

from nerve dysfunction, which contributes to the epitheliopathy. Limbal stem cells are also affected in sustained hyperglycemia, which hinders the normal regeneration of the epithelium.

The decrease in corneal sensitivity contributes to the severity of dry eye and predisposes patients to corneal trauma, which entails an increased risk of developing neurotrophic corneal ulcers and can adversely affect corneal healing ${ }^{34}$.

\section{Diagnosis}

In the literature, some researchers describe that in diabetic patients corneas have a tendency to show a statistically significant higher central thickness, ${ }^{35}$ due to pleomorphism and polymegatism compared to corneas of patients without DM.

\section{Treatment}

Diabetic epitheliopathy can be treated with lubricants, antibiotics, therapeutic contact lenses and tarsorraphy; all this treatments generate favorable conditions for healing. Failures of conventional methods to improve epithelial repair relate to greater symptoms of pain and discomfort in patients and they also provide an opportunity for infections that can lead to devastating visual problems. Furthermore, none of these therapies aims at the pathophysiology of the delay in corneal reepithelialization secondary to DM, which is why metabolic control of the patient is essential ${ }^{36}$.

Some studies have shown that growth factors and cytokines can significantly improve epithelialization (epithelial proliferation and migration) and, consequently, accelerate epithelial healing. More recently, improvement and a significant increase in healing corneal rate were demonstrated with the topical administration of insulin, naltrexone and nicergoline ${ }^{37}$.

\section{Conclusion}

There are several causes of corneal epitheliopathy, so it is important to consider the most frequent ones for proper diagnosis and treatment. Among the rare causes of corneal epitheliopathy are the toxic, nutritional and inflammatory, from which diabetic epitheliopathy is the most important one. These conditions must be intentionally sought out in ophthalmological practice in cases of persistent epitheliopathies or those refractory to conventional treatment.

The ophthalmologist must be aware and identify these causes for proper management and to avoid complications that can affect vision irreversibly.

\section{References}

1. Edelhauser HF, Ubels J. The cornea and the sclera. En: Kaufman PL, Alm A, eds. Adler's Physiology of the Eye. 10. ${ }^{a}$ ed. St. Louis, MO: Mosby; 2003. p. 47-114

2. Grant WM. Toxicology of the Eye. Springfield, IL: Charles CThomas; 1986.

3. Chen W, Li Z, Hu J, Zhang Z, Chen L, Chen Y, Liu Z. Corneal alternations induced by topical application of benzalkonium chloride in rabbit. PLoS One. 2011;6(10):e26103.

4. Chen HT, Chen KH, Hsu WM. Hsu Toxic keratopathy associated with abuse of low-dose anesthetic: a case report. Cornea. 2004;23(5):527-9.

5. Burstein NL. Corneal toxicity of topically applied drugs, vehicles and preservatives. Surv Ophthalmol. 1980;25(1):15-30.

6. De Saint Jean M, Brignole F, Bringuier AF, Bauchet A, Feldmann G, Baudouin C. Effects of benzalkonium chloride on grows and survival of Chang conjunctival cells. Invest Ophthalmol Vis Sci. 1999;40(3):619-30.

7. Vignesh AP, Srinivasan R, Karanth S. A case report of severe corneal toxicity following $0.5 \%$ topical moxifloxacin use Case Rep. Ophthalmol. 2015;6(1):63-5.

8. Mian SI, Gupta A, Pineda R $2^{\text {nd }}$. Corneal ulceration and perforation with ketorolac tromethamine (Aculr R) use after PRK. Cornea. 2006;25(2):232-4.

9. Kim YJ, Payal AR, Daly MK. Effects of tear gases on the eye. Surv Ophthalmol. 2016;61(4):434-42.

10. Spector J, Fernandez WG. Chemical, thermal, and biological ocular exposures. Emerg Med Clin North Am. 2008;26(1):125-36, vii.

11. Goldman DR, Seefeld AW. Ocular toxicity associated with indirect exposure to African spitting cobra venom. Wilderness Environ Med. 2010; 21(2):134-6

12. Saint-Jean A, Sainz de la Maza M, Morral M, Torras J, Quintana R, Molina JJ, et al. Ocular adverse events of systemic inhibitors of the epidermal growth factor receptor: report of 5 cases. Ophthalmology. 2012;119(9):1798-802

13. Graue-Hernández EO, Navas A, Ramírez-Miranda A. Toxic keratoconjunctivitis. En: Holland EJ, Mannis MJ, Lee WB, eds. Ocular surface disease: cornea, conjunctiva and tear film. Atlanta: Elsevier; 2013. p. 189-93.

14. Dart J. Corneal toxicity: the epithelium and stroma in iatrogenic and factitious disease. Eye (Lond). 2003;17(8):886-92.

15. Patel S, Dhakhwa K, Rai SKC, et al. Clinical profile of toxic keratoconjunctivitis after ocular trauma with insect. Journal of Universal College of Medical Sciences. 2013;1(4):41-4 
16. Wilson FM $2^{\text {nd }}$. Adverse external ocular effects of topical ophthalmic therapy: an epidemiologic, laboratory, and clinical study. Trans Am Ophthalmol Soc 1983;81:854-965.

17. Tok OY, Tok L, Atay IM, Argun TC, Demirci N, Gunes A. Toxic keratopathy associated with abuse of topical anesthetics and amniotic membrane transplantation for treatment. Int J Ophthalmol. 2015;8(5):938-44.

18. Barbaro V, Ferrari S, Fasolo A, Pedrotti E, Marchini G, Sbabo A, et al. Evaluation of ocular surface disorders: a new diagnostic tool based on impression cytology and confocal laser scanning microscopy. Br J Ophthalmol. 2010;94(7):926-32.

19. Reilly CD, Mannis MJ. Toxic conjunctivitis. En: Krachmer JH, Mannis MJ Holland EJ, eds. Cornea - Fundamentals, Diagnosis and Management. St. Louis: Mosby; 2011. p. 613-21.

20. Altinok AA, Balikoglu M, Sen E, Serdar K. Nonpreserved amniotic membrane transplantation for bilateral toxic keratopathy caused by topical anesthetic abuse: a case report. J Med Case Reports. 2010;4:262.

21. Steinkuller PG, Du L, Gilbert C, Foster A, Collins ML, Coats DK. Childhood blindness. J AAPOS. 1999;3(1):26-32.

22. Smith J, Steinemann TL. Vitamin A deficiency and the eye. Int Ophthalmol Clin. 2000;40(4):83-91.

23. Ehrlich HP, Tarver H, Hunt TK. Effects of vitamin A and glucocorticoids upon inflammation and collagen synthesis. Ann Surg. 1973;177(2):222-7.

24. Herbort CP, Weissman SS, Ostler HB, Cevallos A, Char DH. Ocular surface keratinization as a predictor of response to topical retinoic acid therapy. Arch Ophthalmol. 1989;107:1275-6.

25. Sommer A. Effects of vitamin A deficiency on the ocular surface. Ophthalmology. 1983;90(6):592-600.

26. Chander A, Chopra R, Batra N. Vitamin A deficiency: an eye sore. J Med Nutr Nutraceut. 2013;2:41.
27. Asselineau D, Bernard BA, Bailly C, Darmon M. Retinoic acid improves epidermal morphogenesis. Dev Biol. 1989;133(2):322-35.

28. Herbort CP, Zografos L, Zwingli M, Schoeneich M. Topical retinoic acid in dysplastic and metaplastic keratinization of corneoconjunctival epithelium. Graefes Arch Clin Exp Ophthalmol. 1988;226(1):22-6. $\infty$

29. Kruse FE, Tseng SC. Retinoic acid regulates clonal growth and differentiation of cultured limbal and peripheral corneal epithelium. Invest Ophthalmol Vis Sci. 1994;35(5):2405-20.

30. Zouboulis CC. Isotretinoin revisited: pluripotent effects on human sebaceous gland cells. J Invest Dermatol. 2006;126(10):2154-6.

31. Saini JS, Khandalavla B. Corneal epithelial fragility in diabetes mellitus. Can J Ophthalmol. 1995;30(3):142-6

32. Inoue K, Kato S, Ohara C, Numaga J, Amano S, Oshika T. Ocular and systemic factors relevant to diabetic keratoepitheliopathy. Cornea. 2001; 20(8):798-801.

33. McNamara NA, Brand RJ, Polse KA, Bourne WM. Corneal function during normal and high serum glucose levels in diabetes. Invest Ophthalmol Vis Sci. 1998;39(1):3-17.

34. Hyndiuk RA, Kazarian EL, Schultz Rom Seideman S. Neurotrophic corneal ulcers in diabetes mellitus. Arch. Ophthalmol. 1977;95(12): 2193-6.

35. Inoue $\mathrm{K}$, Kato $\mathrm{S}$, Inoue $\mathrm{Y}$, Amano $\mathrm{S}$, Oshika $\mathrm{T}$. The corneal endothelium and thickness in type II diabetes mellitus. Jpn J Ophthalmol. 2002;46(1):65-9.

36. Kaji Y. Prevention of diabetic keratopathy. Br J Ophthalmol. 2005;89(3): 254-5.

37. Abdelkader H, Patel DV, McGhee CNj, Alany RG. New therapeutic approaches in the treatment of diabetic keratopathy: a review. Clin Exp Ophthalmol. 2011;39(3):259-70. 